sea-level phases, rather than simply by shore wave action on exposed continental shelf sediments. If the latter process was widely developed, it is thought that barrier reef establishment would have been inhibited or prevented. A possible counter to this argument, namely, that the muddy fraction of the shelf edge sediments would have been winnowed out during the early part of a low sea-level stand, is weakened by the fact that it would reduce the time interval of effective erosion by such inferred shore suspension currents too greatly.

Of the Murray submarine canyons, off the South Australian coast, little is yet known. They were located by the naval survey vessel H.M.A.S. Lachlan, by tracing the 100-fathom line for about eighty miles in the vicinity of the Murray River mouth. The deep submarine canyon structures occur in a width of less than four miles, although the remainder of the survey course revealed no other significant break.

The submarine canyons are thought to be genetically related to drowned courses of the Murray River, which is the only large river at present entering the sea locally. Along the line of the echo-sounding traverse, the three structures, named respectively the West, Central and East Murray submarine canyons, bottomed at approximately 550, 625 and 750 fathoms. The central and east members are separated by a low but definite ridge.

It is not known whether the three submarine canyons are essentially parallel structures or part of an elongated dendritic pattern. Investigations to be carried out in the future should solve this problem.

Concerning canyon triplicity, in a paper on the two groups of submarine canyons now in the press ${ }^{2}$, I have advanced two theories as alternative possible explanations. Both relate to the repeated sea-level falls of the Pleistocene glacial phases, during which erosion by means of bottom density currents is considered (Daly's theory) to have been at a maximum.

Department of Mines, REg. C. SPRIGg

Flinders Street,

Adelaide.

Oct. 15.

1 Daly, R. A., "The Floor of the Ocean" (Univ. of North Carolina Press, 1942)

'Sprigg, R. C., Trans. Roy. Soc. S. Aust., in the press.

\section{Units and Useful Range in Photo-electric Colorimetry}

WE value the remarks of Drs. Edisbury, Taylor and Gridgeman ${ }^{1}$ on a new unit in photo-electric colorimetry ${ }^{2}$. Opinions do not seem at variance that measurements should be made at approximately the same optical density ${ }^{1,2}$, that-provided the Beer-Lambert law be valid-the relation of the

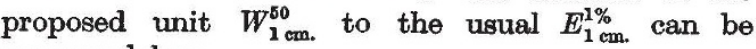
expressed by :

$$
E_{1 \text { em. }}^{1 \%}=\frac{0 \cdot 00301}{W_{1 \mathrm{~cm} .}^{50}},
$$

and that $E(1 \%, 1 \mathrm{~cm}$.$) is certainly less cumbersome$ to print than $E_{1 \% \mathrm{~m}}^{1 \%}$. Title and text of our letter ${ }^{2}$, however, should have made it clear that we had photo-electric colorimeters (absorptiometers) in mind. Though it was shown by Twyman and Lothian ${ }^{3}$ that 0.4343 is the best density for this type of instrument, it was also stated that ". . we may use densities between 0.2 and 0.8 without any considerable loss of accuracy". This range covers easily the proposed half-value and adjacent auxiliary readings used for interpolating $W_{1 \mathrm{~cm}}^{50}$. An even wider range $(0 \cdot 2-1 \cdot 2)$ is recommended elsewhere for an instrument other than ours. The statement ${ }^{1}$ that $E(1 \%, 1 \mathrm{~cm}$.$) is$ merely a standard expression that does not carry the implication that one must measure the optical density of a 1 per cent solution in a $1 \mathrm{~cm}$. cell may probably be correct, but not necessarily so, and does not seem to be endorsed unanimously; for Guild ${ }^{5}$ inferred regarding accuracy in spectrophotometry that ". . . our terminology should be kept in as close correspondence as possible with the physical magnitudes actually handled in our experiments", strongly deprecating the use of derived magnitudes. Though the proposed half-value is inversely related to quantity, this need not impair its applicability; for a similar magnitude, the half-value layer is a standard expression in X-ray technique ${ }^{6}$.

Thus the major practical point in dispute seems to be, how far the useful range extends towards both ends of the scale. As many extraneous factors influence the final accuracy, the limits of the useful range have to be established by experiment. To test this, sample and blank are compared, say, twenty times, whence a mean and its standard deviation are obtained. From the mean plus/minus sigma, and from the Beer-Lambert law, the error prevailing at this point of the scale can be estimated. A few pilot measurements towards either end of the scale will readily establish fiducial limits. 920 measurements performed on different concentrations of copper sulphate in water did not reveal any significant difference in accuracy between 10-90 per cent transmission. Within this range, two thirds of all observations fell within the limits $\pm \mathbf{0 . 8 8}$ per cent weight of copper sulphate. The corresponding error below and above this range was $2 \cdot 60$ per cent and $2 \cdot 56$ per cent respectively.

\section{Department of Hygiene, Hebrew University, Jerusalem.} Nov. 3.

${ }^{1}$ Edisbury, J. R., Taylor, R. J., and Gridgeman, N. T., Nature, 159, 777 (1947).

${ }^{2}$ Koch, W., and Kaplan, D., Nature, 159, 273 (1947).

${ }^{8}$ Twyman, F., and Lothian, G. F., Proc. Phys. Soc., 45, 643 (1933).

- Glover, J., Goodwin, T. W., and Morton, R. A., Biochem. J., 41, 97 (1947).

${ }^{5}$ Guild, J., Proc. Phys. Soc., 45, 659 (1933).

- Pohle, E. A. and Chamberlain, W. E., "Theoretical Principles of Roentgen Therapy" (Lea and Febiger, Philadelphia, 1938).

THE major practical point in dispute is not "how far the useful range extends towards both ends of the scale" (though we believe this to be narrower than many published figures imply), but whether the proposed new unit fulfils any useful function not already covered by the old; and on this issue we have nothing to add to our original arguments. We would ask only that anyone who still prefers to use the 'half-value' should also, for the convenience of the reader, give the equivalent $E(1 \%, 1 \mathrm{~cm}$.$) value.$
J. R. EDISBURY
R. J. TAYLOR
N. T. Gridghman

Research Department, Lever Bros \& Unilever, Ltd., Port Sunlight, Cheshire. 